\title{
Strategic Planning in an Academic Context
}

\author{
W. Spencer Smith \\ Director, Engineering 1 \\ Computing and Software \\ McMaster University, Hamilton, Ontario, Canada \\ smiths@mcmaster.ca
}

\begin{abstract}
This paper presents a document driven strategic planning process for academic units. Details are provided on the steps in the process that will lead, with a reasonable investment of time and effort, to a quality strategic plan document that incorporates input from all stakeholders. The resulting plan consists of a mission statement, vision statement, goals, objectives and implementation ideas. The specific organization of the elements of the plan and tables for systematically presenting the details on definitions, relationships between components, evaluation criteria and timelines are presented using a template. The proposal for the template approach is motivated by the success of this approach in software engineering practise. The template facilitates producing a document that is complete, consistent, understandable and maintainable. The process and the final product are illustrated using examples from Engineering 1 at McMaster University.
\end{abstract}

\section{Introduction}

A strategic plan provides an explicit statement that will guide an organization as it moves forward. The time is right for many academic units to produce strategic plans because of our challenging financial times and a need to use our limited resources as effectively as possible. Moreover, many engineering faculties and departments have a need for strategic planning as they revise their curriculum and its administration in light of the current push from the Canadian Engineering Accreditation Board (CEAB) for outcomes based assessment. Given the need for a strategic plan, the question is what approach can be adopted by academic units for its development that engages all stakeholders and produces a useful document? Many ideas are presented in the strategic planning literature [1, 2], but how can these ideas be applied in an academic context? In particular, what planning process will have the following properties:
- Suitable for the department level, but with the potential to scale up.

- Not too resource intensive.

- Easy to follow and understandable.

- Produces a quality finished product.

With respect to the quality of the finished product, the qualities of interest include the following: consistent, complete, traceable, abstract, unambiguous, understandable and maintainable.

The idea proposed in this paper is to adopt the strategic planning processes presented in the literature together with ideas from software engineering. In particular, the proposed approach is to use ideas from requirements elicitation, analysis and documentation to improve the quality of the planning documentation. The process proposed here, illustrated through the case of strategic planning in Engineering 1 at McMaster, uses a document driven approach. The process centres around a strategic plan template, consisting of document headings and guidance on section contents. A process that engages the stakeholders is proposed for filling in and revising the document contents through several iterations. The next section details the proposed approach.

\section{Proposed Approach}

The purpose of the strategic plan is to specify the vision for an academic unit and provide measurable objectives on the progress toward achieving this vision. The first section below summarizes the document driven process proposed to achieve this. The next section presents the template for the document used to drive the planning process. After this overview, the discussion is broken down into separate sections on the main parts of the template, including sections on the mission statement, vision statement, goals, objectives and implementation ideas. 


\subsection{The Process}

The elements of the process used for planning presented here are not new. They come from the strategic planning literature and from techniques for requirements elicitation and analysis. The steps given in this section are a specific description of what elements from the literature worked in the case of Engineering 1 at McMaster University. Given that the context for planning at McMaster is similar to the context for other academic institutions, there is reason to believe that these steps would also be successful elsewhere. The steps in the proposed process are summarized below. These steps were selected with the goal of not being too onerous on people's time, while still facilitating the creation of a strategic plan that is complete in the sense that no major issues are likely to have been missed. The steps below assume that there is a person, termed the facilitator, that is in charge of the process.

1. The facilitator forms a strategic planning group. The group should be large enough to bring a variety of ideas, but no so large as to be unwieldy. The group should include representatives from the various stakeholder groups, including members of the academic unit, members of related academic units, staff and students. In the case of Engineering 1 the planning committee consisted of 12 members, including volunteers from the Engineering 1 Operating Committee.

2. The group performs a SWOT (Strengths, Weaknesses, Opportunities and Threats) analysis. This analysis sets a context for the future planning meetings and it is summarized in the strategic plan.

3. The group brainstorms on the mission statement, vision statement, goals and objectives. Although the brainstorming can be guided by the definitions of goals and objectives (as given in Section 2.2), the classification should not be emphasized during brainstorming, as this will tend to stifle creativity. In particular, if participants come up with implementation ideas (defined in Section 2.2) these ideas should be recorded without interrupting the discussion.

4. The facilitator takes the products of the brainstorming session and produces a rough document, where each idea is properly classified as a goal, objective or implementation idea.

5. The facilitator reviews other related planning documents and refines the goals, objectives and implementation ideas. In the case of Engineering 1 at McMaster, the most significant other document considered was the Faculty strategic plan [3].

6. The facilitator presents the classification to the planning group for discussion and refinement.

7. The planning group votes on the goals and keeps those that score the highest. In the case of Engineering 1, each group member was given 10 "votes" to spend as they saw fit on the 7 identified goals. After totalling the votes, it became obvious that 3 goals had a much higher priority than the others.

8. The facilitator drafts the strategic plan following the given template (see Section 2.2).

9. The facilitator brings the plan to the various bodies required for approval and iterates based on their feedback. In the case of Engineering 1 the draft went through iterations with the strategic planning group, the Engineering 1 Operating Committee, the Associate Dean (Academic) and the Dean of Engineering.

10. The plan becomes official and is now shared with all stakeholders.

11. The implementation phase of the plan begins. This phase is guided by the objectives identified in the plan.

12. The plan is revisited with an oversight committee on a periodic basis to see the progress on the objectives. In the case of Engineering 1, the Director of Engineering 1 will provide an annual progress report to the Engineering 1 Operating Committee.

\subsection{Strategic Plan Template}

A document driven approach was selected for producing the strategic plan. The process centres around a strategic plan template, consisting of document headings and guidance on section contents. The template provides a frame of reference, identifies needed information, and suggests an order of presentation so that the strategic plan can be best expressed. As described in the previous section, this template is filled in and edited through several iterations. The advantages of the document driven approach are as follows: i) the template provided guidance for the process of strategic planning, ii) the template potentially increases the adequacy of the strategic plan because it provided a well-organized format for the document, which acts as a checklist for the writers of the plan and reduces the chances of omitting information, iii) the template facilitates communications among the various stakeholders, and iv) the template encourages a 
1. Introduction

2. Scope and Purpose

3. Mission

4. Vision

5. Goals

- Goal 1

- Goal 2

- $\ldots$

6. Ideas for Implementing the Plan

7. Acknowledgements

A. Template for the Strategic Plan

B. Current Situation

- Courses, People and Resources

- Strengths and Weaknesses

- Opportunities and Threats

Figure 1: Table of Contents for the Strategic Plan

systematic procedure. These advantages of a template are discussed, for instance, in [4, 5] in the context of requirements documentation.

A good template improves the qualities of the final strategic plan. For instance, the predefined structure helps to improves completeness and consistency of the documentation. Without the template, it would be easy to forgot details such as providing a timeline for all objectives. The logical ordering of the template assists with understandability, which in turn assists with maintainability. To further improve maintainability the template should have the quality of traceability; that is, the template should enforce documentation of the relationship between its internal components and with external components, such as other planning documents.

The proposed template is summarized in Figure 1 This template uses a combination of the template followed for the Faculty strategic plan [3] and the Strategic Plan Template from the National States Geographic Information Council [6].

The template for the strategic plan suggests starting with an Introduction and an explicit statement of the plan's Scope and Purpose. Following this the plan presents the Mission Statement (Section 2.3). This statement summarizes the purpose of the academic unit; that is, the mission statement gives the reason for the ex- istence of the academic unit. The next section (Section 2.4 provides the Vision Statement for the strategic plan. The vision statement specifies what the strategic plan hopes to see achieved over the time period of the plan. The vision statement does not say how the future state of the academic unit will be obtained; it only summarizes what is desired. The next section, Section 2.5 summarize the goals that will need to be reached to obtain the stated vision. Each of the goals of the plan is presented in its own subsection. Ideas for Implementing the Plan are presented next. The plan ends with Appendices that summarize the Template for the Strategic Plan and the Current Situation. This information is given so that readers have the opportunity to judge the methodology used for producing the document and the context in which the planning took place. Details of this sort are often presented earlier in strategic plans, but they were moved to appendices here so that the document can focus on the more exciting material. Some audiences will not care about the template used or may already be familiar with the current status of the academic unit. For these readers placing this material in appendices should help them focus on the most important and relevant portion of the plan from their perspective.

Management of the strategic plan document can be facilitated by technology. For instance, LaTeX (LTEX) can be used for formatting, automatic numbering and cross referencing. To keep the formatting consistent and complete, new commands can be defined for formatting each goal, objective and implementation idea.

\subsection{Mission Statement}

The mission statement provides the purpose for the academic unit; it defines the unit's raison d'être. Whereas the vision statement is what is going to be changed or improved in the future, the mission of the unit is the same in the past, present and future. The early brainstorming sessions with the strategic planning group will record the academic unit's mission statement. A sample mission statement, taken from Engineering 1 at McMaster is provided in Figure 2

\subsection{Vision Statement}

A sample vision statement is shown in Figure 3, The vision statement shows the improvements and changes the academic unit would like to make in the future. The vision is to be realized over the life of the strategic plan. Typical planning horizons are 3 to 5 years.

\subsection{Goals}

Goals are high level abstract statements of the things that need to be achieved to meet the proposed vision. Goals are opative statements (expressing a wish or hope) that refer to intended properties of the system in the fu- 
1. Educate the students so that they are prepared for success in Level 2 Engineering and beyond by providing them with a solid foundation in the engineering fundamentals that are common to all Engineering departments.

2. Give the students exposure to each of the Level 2 Engineering disciplines so that they understand what Engineering is, what Engineers do, and so that they are prepared for multidisciplinary projects in their futures.

3. Deliver the first year curriculum and student services in a positive learning environment that facilitates the transition to University, fosters student success and contributes to the quality of student life.

Figure 2: Example Mission Statement for Engineering 1

To build a strong Engineering 1 community, incorporating the Students and the Faculty and Staff members from both Engineering and Science. Internally, a strong community will provide tangible benefits for the Students, in terms of such measures as performance and retention, and for the Faculty and Staff members, in terms of such measures as teaching evaluations, research productivity and job satisfaction. Externally, a strong community will assist with recruitment, building on the Faculty's vision of sustainability, and with providing well prepared students for our Level 2 programs.

Figure 3: Example Vision Statement for Engineering 1

\begin{tabular}{|l|l|}
\hline Number: & G1 \\
\hline Label: & G-EngineeringEducation \\
\hline Description: & $\begin{array}{l}\text { To be recognized nationally for peda- } \\
\text { gogical methods and measures for en- } \\
\text { gineering education. }\end{array}$ \\
\hline $\begin{array}{l}\text { Related } \\
\text { Items: }\end{array}$ & $\begin{array}{l}\text { FSP-UG-G8, FSP-UG-G8-O1, FSP- } \\
\text { UG-G8-O2, O- ImproveQualityOfEd- } \\
\text { ucation, O- ResearchOutput, O- Re- } \\
\text { searchFunding, O- ModelForFaculty }\end{array}$ \\
\hline
\end{tabular}

Figure 4: Example Goal

ture [7]. The goals provide the direction for reaching the vision. Each goal statement is presented in this document using a tabular structure. The rows for the goal statements have the following purposes:

Number: The goals are assigned a unique number, which takes the form of a natural number with the prefix "G." This number will be used for purposes of cross-referencing and traceability within this document.

Label: The label is a short identifying phrase, each with the prefix "G." This label provides a mnemonic that helps with quickly remembering which goal is being presented. Furthermore, the label will be useful when an external document needs to reference one of the goals in this document.

Description: The description of the goal is given here.

Related Items: A related item is a goal or an objective that is used by the current goal. If the source of the goal or objective is the Faculty Strategic Plan, it will be references by FSP, followed by UG (Undergraduate) or Intro (for the introductory section of the plan), G\# (the goal number) and, if appropriate, O\# (the objective number).

A sample goal is provided in Figure 4. Within the strategic plan document the related items will ideally be provided as hyperlinks, to assist with navigation of the documentation. This allows one to quickly visit the associated goals and objectives. The actual strategic plan generates numbered cross references in the related items field, but as this current document cannot include all of the referenced items, they are listed by name instead.

The other two goals identified in the strategic plan for Engineering 1 are:

G2 Improve Performance: While maintaining or improving academic standards, improve the academic performance of the first year class. 


\section{G3 Improve Quality of Student Experience:}

Improve the satisfaction, enjoyment, reward and sense of community of being a student in Engineering 1. Provide the class with sense that they are a part of something special.

\subsection{Objectives}

To be able to plan for the future, the goals need to be further decomposed into objectives, which are similar to goals, but more specific and measurable. Following the practise used for requirements in software engineering, the criteria for good objectives is that they be abstract (free of implementation decisions), unambiguous, validatable, and consistent. The strategic plan will not include specific design decisions, such as proposed curriculum changes, rather it will outline the objectives, which may later be met by curriculum changes. Objectives are presented using a similar tabular structure as that employed for goals. Objectives add the following headings to the previously described tabular structure:

Evaluation: The criteria used to measure whether the objective has been achieved. To make measuring progress on the plan meaningful it is necessary to quantify the progress toward the stated objective.

Timeline: The proposed start and end date for the objective.

An example objective is given in Figure 5 This objective is one of the related items from the goal in Figure 4. As for the goal, the related items here are listed by name, not number.

In the case of the plan for Engineering 1 the 3 goals were decomposed into 16 objectives. Objectives include being recognized nationally for pedagogical methods and measures for engineering education, reducing attrition rates, increasing the perception among the students that the faculty and staff have a personal interest in them, and revising the Engineering 1 curriculum to incorporate more material on sustainability.

\subsection{Implementation Ideas}

The purpose of the strategic plan is to specify the vision for the academic unit and provide measurable objectives on the progress toward achieving this vision. The plan is intended to specify "what" needs to be achieved, not "how" to achieve it. However, in the process of brainstorming for the plan, many "how" ideas will inevitably arise. Rather than potentially lose these ideas, they are recorded in a separate section. As for the goals and objectives, each implementation idea is also presented in tabular form, using the four headings: "Number," "Label," "Description," and "Related Items." An idea of

\begin{tabular}{|l|l|}
\hline Number: & O2 \\
\hline Label: & O-ResearchOutput \\
\hline Description: & $\begin{array}{l}\text { Increase the pedagogical research out- } \\
\text { put by Engineering 1 instructors, espe- } \\
\text { cially for the teaching professors. }\end{array}$ \\
\hline $\begin{array}{l}\text { Related } \\
\text { Items: }\end{array}$ & $\begin{array}{l}\text { FSP-UG-G8-O1, FSP-UG-G8-O2, G- } \\
\text { EngineeringEducation, O- Research- } \\
\text { Funding, O- ModelForFaculty, O- Re- } \\
\text { duceAttrition, I- Logbook, I- Motiva- } \\
\text { tionResearch, I- LatentSemanticAnal- } \\
\text { ysis, I- ExperimentalSection, I- VDI, } \\
\text { I- MapleSim, I- EllipticalLab2, I- } \\
\text { RemoteManagementSoftware, I- Self- } \\
\text { AssessmentAndPractise, I- iClicker, I- } \\
\text { DocumentationOfCurriculum, I- Expe- } \\
\text { rientialLearning }\end{array}$ \\
\hline Evaluation & $\begin{array}{l}\text { As long as appropriate funding is avail- } \\
\text { able (O-ResearchFunding), produce an } \\
\text { average of one journal paper or 3 con- } \\
\text { ference papers per year. }\end{array}$ \\
\hline Bimeline & By 2012 \\
\hline
\end{tabular}

Figure 5: Example Objective

which implementation ideas relate to which objectives is provided through the "Related Items" field for each implementation and each objective.

Figure 6 shows a sample implementation idea. As for the goals and objectives, the related items are listed by name in this paper, but by number in the actual strategic plan.

The implementation ideas are not a formal part of the plan. The intention of the strategic plan is not that all implementation ideas will be pursued. The decision on which implementation ideas to pursue will be made by the people assigned to the task of realizing the objectives. Those making plans to reach the objectives are not constrained in any way by the implementation ideas recorded in the strategic plan; they are free to use these ideas or come up with new ones. In the case of the Engineering 1 strategic plan there are 44 implementation ideas. Ideas include creating an experiential learning centre, building a database to track and analyse student grades, and planning social events for the Engineering 1 community. These ideas provide a potential starting point for making the strategic vision a reality.

\section{Conclusion}

This paper presents a document driven process for strategic planning for academic units. The process is based on successful methodologies that are documented in the strategic planning literature, together with ideas from software engineering. From the strategic planning 


\begin{tabular}{|l|l|}
\hline Number: & I7 \\
\hline Label: & I-ExperimentalSection \\
\hline Description: & $\begin{array}{l}\text { Investigate the addition of an experi- } \\
\text { mental section in one of the first year } \\
\text { Engineering courses (ENGINEER 1C, } \\
\text { 1D or 1P). This section would be run } \\
\text { differently from the main sections. Its } \\
\text { purpose would be to investigate new } \\
\text { methods of course delivery and instruc- } \\
\text { tion. Enrolment in this section would } \\
\text { be entirely optional, with a cap around } \\
50 \text { students. The course would poten- } \\
\text { tially be more advanced than regular } \\
\text { sections. One possible idea is to use } \\
\text { problem based learning in the special } \\
\text { section. }\end{array}$ \\
\hline Items: & $\begin{array}{l}\text { O-ResearchOutput, O-HighAchievers } \\
\text { Ifelated }\end{array}$ \\
\hline
\end{tabular}

Figure 6: Example Implementation Idea

literature come the ideas to include a mission statement, a vision statement, goals, objectives, SWOT, brainstorming and timelines. From the software engineering literature, specifically the requirements documentation literature, come the ideas of a documentation template, labels and traceability between goals, objectives and implementation ideas, and strict adherence to the principle of abstraction. Documenting the objectives in an abstract form is as helpful for strategic planning as for any requirements document. At the planning stage we do not want to constrain the solutions that can be designed by those tasked with realizing the proposed vision.

\section{Acknowledgements}

The advice and feedback of the Engineering 1 Strategic Planning Committee is gratefully acknowledged. The committee consisted of the following individuals: Qingsha Cheng, Thomas Doyle, William Farmer, Robert Fleisig, Ray LaPierre, Ruth Nicholson, Jennifer Stoneburgh, Erinn Van Wynsberghe, Maria White, Sally Williams and Hatem Zurob. In addition, the Associate Dean (Academic), Ken Coley, provided several very useful comments on the documentation.

\section{References}

[1] M. Lorenzen, "Strategic planning for academic library instructional programming," Illinois Libraries, vol. 86, no. 2, pp. 22-29, Summer 2006.

[2] L. Parker Gates, "Strategic planning with critical success factors and future scenarios: An integrated strategic planning strategic planning with critical success factors and future scenarios: An integrated strategic planning framework," Software Engineering In- stitute, Carnegie-Mellon University, Tech. Rep. CMU/SEI-2010TR-037, November 2010.

[3] Faculty of Engineering, "Engineering a sustainable society," McMaster University, http:// www.eng.mcmaster.ca/ strategicplan/ index.html, Strategic Plan, 2009.

[4] B. Sanga, "Assessing and improving the quality of software requirements specification documents (SRSDs)," Thesis for M.Sc. Program, Computing and Software Department, McMaster University, Hamilton, ON, August 2003.

[5] I. Sommerville and P. Sawyer, Requirement Engineering: A Good Practice Guide. John Wiley \& Sons Ltd., 1997, iSBN 0-47197444-7.

[6] Applied Geographics, "Strategic plan template," National States Geographic Information Council (NSGIC), www.nsgic.org/hottopics/strategic_plan_template.pdf, Contract 05HQCN0034, March 2006.

[7] A. van Lamsweerde, "Goal-oriented requirements engineering: a guided tour," in Proceedings of the 5th IEEE International Symposium on Requirements Engineering, IEEE. IEEE Computer Society, Washington, DC, USA, August 2001, pp. 249-263. 